\title{
Coating Bio-Resistance Test of Different Wall Finishing for Isolated Indoor Fungal Treatment by Using Potassium Sorbate Biocide on Wood
}

\author{
U.K. Parjo ${ }^{1 *}$, N. M. Sunar ${ }^{1}$, A.M. Leman ${ }^{1}$, P.Gani ${ }^{2}$, Q. Emparan², \\ C.M. $\mathrm{Er}^{2}$
}

${ }^{1}$ Department of Chemical Engineering Technology, Faculty of Engineering Technology (FTK), Universiti Tun Hussein Onn Malaysia (UTHM), 86400, Parit Raja, Batu Pahat, Johor, Malaysia

${ }^{2}$ Department of Water and Environmental Engineering, Faculty of Civil and Environmental Engineering (FKAAS), University Tun Hussein Onn Malaysia (UTHM) 86400, Parit Raja, Batu

Pahat, Johor, Malaysia

\author{
1*umi5506@yahoo.com, 1'shuhaila@uthm.edu.my,1.'mutalib@uthm.edu.my, \\ 2parancgat@yahoo.com, 22quinston89@gmail.com, 2erchinming@hotmail.com,
}

Keywords: Indoor air quality, potassium sorbate, wall finishing, wood

\begin{abstract}
Malaysia is located on the equator has resulted in having two seasons wet and dry. Both of the seasons can influence indoor air quality of buildings promoting the growth of fungal. Fungal growth can occur with the combinations of temperature, relative humidity, substrate and others. Indoor and outdoor air quality is essential for building occupants to prevent the infection diseases caused by fungal. The goal of this study is to remediate the growth indoor fungal after treated with biocides on different types of wall finishing and evaluate the efficiencies of biocides to treat indoor fungal. In this study, the biocides are utilized as a coating for coating bio-resistance. The measurements of the fungal growth are made by growing the samples on realistic wood substrates on the different wall finishing such as paints and wallpapers. The mold that grew are affecting most of the rooms is selected. The air sampler that have been used to isolate the samples of indoor fungal according to NIOSH Manual Analytical Method (NMAM 0800), a guideline provided by National Institute of Occupational Safety and Health (NIOSH). The fungal growth was evaluated using the ASTM D5590-00 standard measuring on the surface of substrate. The results show that potassium sorbate as biocide was able to reduce the indoor fungal growth depending on the type of material used in the building.
\end{abstract}

\subsection{Introduction}

Malaysia is located near the equator and due to this geographical factor, Malaysia having two seasons, dry and wet season throughout the year. The estimated population of 29 million (Department of Statistics, National), Malaysia is considered as a developing country with the increasing buildings in constructions. However the designs, building systems and the materials used in building constructions promote the fungi growth. The fungi growth are influenced by temperature, relative humidity and other parameters in all climates during all seasons throughout the year. The level of air quality inside and outside the building can be affected by the presence of mold and this situation may cause infection to the occupants in that building. This is because high moist conditions level surrounding and inside the building encourage the growth of fungi. A study done by Spengler [6] stated that the parameter data such as carbon dioxide, temperature and relative humidity can use as significant of ventilation and environmental condition. Lee and Chang [7]also mentioned other air pollution such as sulfur dioxide $\left(\mathrm{SO}_{2}\right)$, temperature, relative humidity, bacteria, formaldehyde( $\mathrm{HCHO})$, nitric oxide( $\mathrm{NO})$ and carbon dioxide anf nitrogen dioxide $\left(\mathrm{NO}_{2}\right)$ are also use as parameters in air quality monitoring. However growing in indoor building, the fungi obtained their carbon source from the material appearing in the building. Carbon is very important element of nutrient that essential for fungi growth. Naturally, the fungi are slowly decomposed plants and 
organic matter as part of their nutrition for carbon source.Several studies have been conducted to determine the level indoor air quality, cause by fungi growth Ibrahim [1] mentioned that the relative humidity and temperature are the environmental factors that can influence the effectivenes of several of fungi to grow. Furthermore there have been found that various factors such as the fungi species [2],[3] the air velocity over the surface and construction building[2] are also affecting mold growing on the surface. According to Mandal and Brand [5], the airborne microorganism will be an environmental hazard when present in high concentrations and result in health problems. The growth of fungi on building surfaces can give health risks and should not be tolerated in indoor environment. Previously Belloti [8]noted that antimicrobial coatings can create healthy environment because it can prevent and protect the bio-deterioration of the substrtes in buildings.There are three principal types of antimicrobial coatings such as microbial repelling, biocide releasing and contact killing. The types of coatings and building material must be green chemical and give the effective in controlling microbial growth. Fungicide is use to control the growth of fungi found in buildings and friendly alternative compounds and non-toxic for human. The studies carried out by Shelton [9]stated discovered that the environmental factors such as high temperature and relative humidity can also contribute to the higher occurrences of indoor fungi. The aim of this research was to enumerate the growth of indoor fungal after incorporate with potassium sorbate at different types of wall finishing and to evaluate the efficiency potassium sorbate when use as a coating on wood for coating-bio resistance.

\subsection{Material and methods}

\subsection{Air sampling equipment and procedure for collecting fungal}

The method used for collecting fungi in this research is biostage single-stage impactor viable cascade impactor (SKC Quick Take 30). The malt extract agar (MEA) is used as culture media for indoor fungal. In the air, impactors are used to collect the particles. The procedure for collecting indoor fungal was conducted according to the NIOSH Manual Analytical Method (NAM 0800). The media that have been used in culturing fungi must be sterilized before used using autoclave with time for autoclaving around 15 minutes to 20 minutes at temperature of $121^{\circ} \mathrm{C}[8]$.

\subsection{Fungal growth}

The temperature was set $25^{\circ} \mathrm{C}$ to incubated agar plate to observe the growth of indoor fungal. Observation was done between 1 to 5 days after air sampling. The result of fungal spore load per sample was expressed as colony forming units (CFU) per cubic meter of air $\left(\mathrm{m}^{3}\right)$. The colony counters are used to count the colonies manually [8].

\subsection{Preparation of suspension spore}

The spores from the cultures are transferred to spore suspension. Belloti[8], stated that to prepare the spore suspension Tween $20(0.005 \%-\mathrm{w} / \mathrm{v})$, sodium chloride $0.85 \%-\mathrm{w} / \mathrm{v})$ and distilled water $(200 \mathrm{ml})$ are used. From subculture the spore suspension was prepared. By using neubauer chamber, the concentration of spores then was adjusted to $0.3-0.5 \times 10^{6}$ spores $/ \mathrm{ml}$.

\subsection{The coating-bio resistance test}

The coating-bio resistance and growth in remediation of indoor fungal was evaluated by using potassium sorbate on different types of material wall finishing which was exposed to relative humidity to encourage fungi growth. Wood substrate have been used such as support with different surface coverings including two different types of paints and wall paper, inoculated with spore of fungi. Each support was covered with four different finishing such as acrylic paint, glycerol-base paint, thin wall papers and $\left(80 \mathrm{~g} / \mathrm{m}^{2}\right)$ and thick wall papers $\left(240 \mathrm{~g} / \mathrm{m}^{2}\right)$. Earlier, sixteen samples of wood were prepared; the woods were cut into small size approximately $50 \mathrm{mmx} 50 \mathrm{~mm}$. The woods were then washed with $60 \%$ ethanol solution to avoid the contamination. The substrates left for some hours before use for coating bio-resistance test11].Potassium sorbate was selected as a 
biocide based on few criteria and prepared accordingly studied by Belloti [8]. The MEA with 0.03\% $(\mathrm{w} / \mathrm{v})$ biocide was poured into two different paints (acrylic paint and glycerol-based paint). Two different wall papers were glued onto wood and biocide was applied on the surface with finishing. Samples are left to dry for 24-48 hours before inoculate with the growth of fungal spores [11]. Then the samples irradiated with UV lamp 40 minute to avoid contamination. The samples were placed in petri-dish with MEA. Each samplewas place a $50 \mu \mathrm{l}$ of the spore suspension was distributed homogenously on surface. The sample was incubated $25^{\circ} \mathrm{C}$ and every 3 days and observed until 15 days.Each tests has done in triplicate at the same length. The visual assessment was made according ASTMD5590-00 Standard Specification.

\section{Results and Discussion}

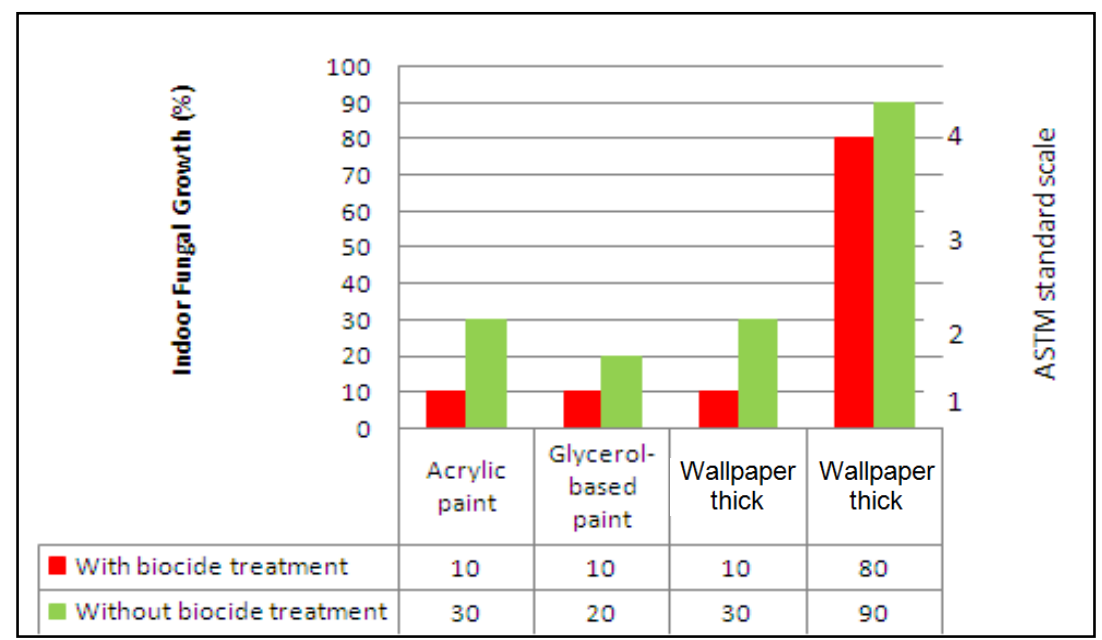

Figure 1: Effect of biocides on wood by using ASTM D5590-00 standard scale

The observation conducted after 15 days in the laboratory. From the coating-bio resistance test, the result presented a comparison a difference between four types of treat wall finishing and untreated wall finishing. Based on the results (Figure1), biocide treatment with acrylic show 20\% reduction of fungal growth and glycerol-based paint shows $10 \%$ the reduction of fungal growth. The paint is raw materials such as pigment dispersion, polymer emulsions, and wetting agents are exposed to microbial degradation. This can be seen by substrate without biocide which is growth rapidly than biocide protection substrate. According to USEPA [12] regulations, the formulated of paint as anti-microbial product, inhibits the growth of mold on paint. The observation of this study showed the biocide treated substrate inhibited the indoor fungi growth in glycerol-based paint. The microbial water-borne coating paints attacked by both nutritionally exacting bacteria and fungi because it can be many source of contamination. It may the substrate appear to give nutritive support for fungal growth. Thus, in adding biocide potassium sorbate to paint can reduce the fungal growth.

The thick wall paper also show $20 \%$ reduction of fungal growth and thin wallpaper the reduction is $10 \%$. Fungi can grow easily when substrate covered by the thin wall papers. This study found the thin wall papers with biocide are not efficient to reduce indoor fungal growth. From the observation a biodegradable material such as wallpaper thin encouraged the indoor fungal grow. This is possibly because the indoor fungal grow well high moisture content. The indoor fungi growth depends on nutrients, moisture, and time (indoor fungi growth between 24 hours and 10 days from the provision of the growing conditions). However, treated wood with paint wall finishing indicated less growth of indoor fungi compared with thin wall paper finishing (Figure 1). 


\section{Conclusions}

This study proved that using potassium sorbate as a biocide gives good indication to treat the indoor fungi in only certain wall finishing. The addition of biocides together with the paint is able to act in reducing indoor fungal growth on the substrates. However the coating with potassium sorbate was found not significantly reduced indoor fungal infestation on the thin wall papers finishing. For the thin wall papers as a biodegradable material influenced the growth capacity of indoor fungal. In common condition, building wood-based product will always give risk of fungi growth. This approved by the applications of biocides on the thin wall papers as the biocides was absorbed by the paper materials. The indoor fungal growth can be anywhere in building especially for building material such as wood. Even the building material such as concrete is poor source for nutrients, it's not the best option to prevent the growth of indoor fungal when the material are wetted. It is recommended that the accurate ability of the biocide capacity as an agent to reduce the fungus will be further studied. The method used in this research could gives good approximation for building practice on several parts of maintenance and has great potential to further implementation.

\section{ACKNOWLEDGEMENTS}

The authors wish thanks to MyBrain15 for sponsorship this research studies. Author also acknowledge to all participant that involved in this research.

\section{REFERENCES}

[1] Ibrahim, M., Rabah, A.B.,Liman, B., Ibrahim, N.T. (2011). Effect of temperature and relative humidity on the growth of Helminthosporiumfulvum, Njbas, 19(1):127-129

[2] Górny, R. L., Reponen, T., Grinshpun, S. A., Willeke, K. (2001). Source strength of fungal spore aerosolization from moldy building material.Atmospheric Environment 35: 4853-4862.

[3] Kildesø, J., Würtz, H., Nielsen, K. F., Kruse, p., Willeke, K., Thrane, U., Gravesen, S., Nielsen, P. A., Schneider, T.(2003). Determination of fungal spore release from wet building materials.Indoor Air 13(2): 148-155.

[4] Mandal, J., And Brandl, H. (2011).Bioaerosol in indoor environment - A review with special reference to residential and occupational locations. Environmental \& Biological Monitoring.4,83-96

[5] Li, Y. (2007). Mould On Building Materials. Lund Institute of Technology:Ph.D. Thesis.

[6] Spengler, J. D., Samet, J. M., \& McCarthy, J. F. (2000). Indoor air quality handbook. In H. A. Burge (Ed.), The fungi (p.45.16). NY: McGraw-Hill Companies.

[7] Lee, S. C.,\&Chang, M. (1999). Indoor air quality investigations at five classrooms. Indoor Air, 9, 134-138

[8]Bellotti, N., Salvatore, L., Deya, C., Panno, M.T.D., Amo, B.D., \&Romagnoli,R. (2013). The Application of Bioactive Compounds from the FoodIndustry to Control Mold Growth in Indoor Waterborne Coatings. Journal of Colloids and Surfaces B: Biointerfaces, pp. 140-144.

[9] Shelton, B. G., Kirkland, K. H., Flanders, W. D.,\&Morris, G. K.(2002). Profiles of Airborne Fungi in buildings and outdoor environments in the United States. Applied and EnvironmentalMicrobiology, 68, 1743-1753. 
[10] Vacher, S., Hernandez, C., Bartschi, C., Poussereau, N.(2010). Impact ofPaint and Wall-Paper on Mould Growth on Plasterboards and Aluminum, Elsevier, Building and Environment, pp. 916-921.

[11]DOSH. (2010).Industry Code of Practice on Indoor Air Quality, Ministry of Human Resources, Malaysia.

[12] United States Environmental Protection Agency (2013). A brief Guide to Mold, Moisture and your Home.United States: EPA 